Max-Planck-Institut für demografische Forschung

Max Planck Institute for Demographic Research

Konrad-Zuse-Strasse 1 - D-18057 Rostock · GERMANY

Tel +49 (0) 3812081 - 0; Fax +49 (0) 3812081 - 202;

http://www.demogr.mpg.de

MPIDR WORKING PAPER WP 2006-030

SEPTEMBER 2006

\title{
The Contextual Database of the Generations and Gender Program
}

Martin Spielauer (spielauer@ demogr.mpg.de)

This working paper has been approved for release by: Vladimir M. Shkolnikov (shkolnikov@demogr.mpg.de), Head of the Laboratory for Demographic Data.

(C) Copyright is held by the authors.

Working papers of the Max Planck Institute for Demographic Research receive only limited review. Views or opinions expressed in working papers are attributable to the authors and do not necessarily reflect those of the Institute. 


\title{
The Contextual Database of the Generations and Gender Program
}

\author{
Martin Spielauer
}

\begin{abstract}
The increasing recognition that the study of human behaviors has to take into account the multiple contexts in which they occur has opened a promising research avenue in social sciences. It also presents new challenges, e.g., to complement micro-level surveys with the collection of meaningful contextual data within a common conceptual framework. The Contextual Database of the Generations and Gender Program aims at responding to the new data demands by providing a comparative collection of around 210 variables on a national and sub-national level, thus complementing the individual-level data collected in the Generations and Gender Survey.
\end{abstract}

Keywords: Database; Multilevel; Comparative; Generations; Gender

\section{Introduction}

This paper describes the conceptual framework and information content of the international Contextual Database of the Generations and Gender Program (GGP). The Contextual Database was developed to complement the core element of the program, the Generations and Gender Survey (GGS), a panel survey with panel intervals of three years. The GGP is expected to generate the main data source for a cross-national, comparative and multidisciplinary study of the dynamics of family relationships in a series of Eastern and Western European Countries, Japan, and Australia. Currently, the data of the first panel wave are becoming available for the first participating countries; data on other countries are to follow in the next few years. The Contextual Database currently provides data for Bulgaria, Russia, Romania, Hungary, and Canada; several other countries are scheduled to follow in later 2006 and 2007.

The Contextual Database includes information on laws and policies that affect age and sequencing norms as well as the consequences and risks associated with the central lifecourse events studied in the GGP. It also contains indicators of general gender and generational relations, and a range of social, economic, and political indicators. 
The Contextual Database is organized in 16 topics, which are:

\begin{tabular}{|llll|}
\hline$\circ$ Demography & $\circ$ Childcare & $\circ$ Education & $\circ$ Unemployment \\
$\circ$ Health & $\circ$ Elderly care & $\circ$ Housing & $\circ$ National Service \\
$\circ$ Economy & $\circ$ Leave & $\circ$ Legal aspects & $\circ$ Culture \\
$\circ$ Labor & $\circ$ Pension system & $\circ$ Health & $\circ$ Politics \\
\hline
\end{tabular}

This contribution is organized as follows. First, we give some general information on the database, including its history, the participating countries, the organization of data collection, and its web implementation. Second, we highlight the extent to which the Contextual Database meets some of the key demands of contextual and multilevel analysis and describe the key measurement dimensions of the Contextual Database. Third, we describe the way in which the database topics are linked to the GGS information content and introduce the list of variables per topic.

The organization of this paper reflects three of the main development goals of the Contextual Database: a theory-based conceptual framework, the support of innovative methods of data analyses, and a deep integration into the GGP. Besides these theoretical considerations, the Contextual Database builds up on an in-depth survey of existing data sources. The database is freely available at the website of the Max Planck Institute for Demographic Research ${ }^{1}$.

\section{Organization}

\subsection{History of the Contextual Database}

The idea of developing a contextual database to complement data collection on the individual-level was expressed as early as in the Family and Fertility Survey program, which preceded the GGP. It was driven by the desire 'to go beyond the analysis of single countries to consider how differences in context shape the processes that seem to be having an impact on these new family patterns' (Goldscheider 2000, p. 1). More generally, it is based on the increasing recognition that micro behavior cannot be explained solely by relations observed on the micro-level and by an increasing interest in comparative research. In the following, 'Designing a Macro-Context for the Generations and Gender Individual Data' was the topic of a contribution by Patrick Festy (2001) presented at the first meeting of the Generations and Gender Informal Working Group in 2001. With the

\footnotetext{
${ }^{1}$ http://www.demogr.mpg.de; "online databases" section.
} 
installation of the Contextual Database Working Group in 2002, the development of a contextual database became an integral part of the GGP ${ }^{2}$.

The activities and discussions alongside the database development are documented in various written contributions, starting from the development of ideas for a contextual database (Festy 2001), concepts of welfare state research that are useful for the conceptual framework (Neyer 2003), and methodological issues (Racioppi and Rivellini 2002). Discussion papers preceding this publication are Spielauer (2004a) and Spielauer (2004b). A feasibility study on data availability was carried out for Bulgaria. The final choice of variables was influenced by comments of national experts from Russia and Austria, and extensive discussions at an international workshop with participants from Germany, Austria, Russia, Bulgaria, France, The Czech Republic, and Hungary.

\subsection{Country participation}

Being an integral part of the GGP, data collection and provision for the Contextual Database is compulsory for all countries participating in the program. The Contextual Database was also recognized as a valuable stand-alone instrument for countries currently not planning to conduct the GGS, e.g. Canada.

By the beginning of 2006, the following countries have indicated to collect contextual data: Australia, Belgium, Canada, Czech Republic, Estonia, France, Lithuania, Georgia, Germany, Hungary, Italy, Japan, Norway, Poland, and Romania. The first countries for which data are available are Bulgaria, Hungary, Russia, Romania, and Canada; Norway and Poland are scheduled to follow by end of 2006.

\subsection{Data collection}

Data collection is de-centralized and carried out by national teams within the GGP member countries. Institutionally, this usually involves both national statistical offices and research institutes or research departments within statistical offices. The provision of policy-data especially requires research expertise in various domains.

Data collection is supported by standardized table templates provided in Excel spreadsheets, detailed data definitions, a commented list of international data sources, and guidelines for data collectors ${ }^{3}$.

Work and time requirements for data collection vary by country due to the different availability of published data and different coverage in international databases. Six personmonths can serve as a guiding value.

\footnotetext{
${ }^{2}$ A list of team members and national representatives who contributed to the development of the database is found in the Appendix.

${ }^{3}$ The respective documents are available at the Contextual Database-website at http://www.demogr.mpg.de
} 


\subsection{Web Implementation}

Technically, the web-implementation of the Contextual Database is realized as an active database-driven web-application. The Contextual Database website includes full documentation both for the user and data collector. It supports fast navigation by country and database topic for fast access to individual tables. Tables are complemented by variable definitions and links to all available corresponding tables of other countries. Besides being displayed as copy/paste-able html-tables, all variables can be downloaded in two alternative formats, namely as individual comma-delimited text files or in form of Excel-workbooks per topic and country.

\section{Conceptual Framework and information content}

In this section, we approach and describe the conceptual framework and data content of the Contextual Database from three perspectives. First we start from defining the main data types from the angle of data analysis, thereby distinguishing time series, policy histories, and cross-sectional regional information. Second, we use theoretical concepts in order to identify and classify key context types and measurement dimensions, which are general indicators and statistical norms, legal norms and regulations, and the welfare state context with the dimensions of social rights, security, equality, and agency. The third approach starts from the GGS questionnaire and identifies 16 key database topics. These belong to four thematic context types: the individual life-course context, the context of generational and gender relations, the socio-economic context, and the cultural context. For each topic, we introduce a list of variables. These are selected on the basis of the described concepts and by keeping in mind the key dependent variables of the GGS: fertility, partnership formation and dissolution, transition to adulthood, and retirement.

\subsection{A database to support comparative and multilevel analysis}

With a view to support a multilevel approach to GGP data, we have to ensure that individual-level data can be linked to their relevant context. This link can be established by time, region, or individual characteristics, e.g. sex, education, or eligibility to policies.

In order to meet the historical depth of the GGS, the Contextual Database provides around 65 national-level time series and 70 policy histories ranging back to 1970 . These variables allow analyzing how changes in context affect individual behaviors and demographic processes. Time series are usually yearly numerical indicators; policy histories give text and standardized numeric descriptions of key policy changes and changes in legal regulations.

In order to capture the regional variation of context, around 60 variables of the contextual database are collected on the regional level. As GGS does not provide individual migration histories, regional information is usually provided for panel years only or in the form of short time-series, which additionally to the cross-sectional variation capture recent regional 
trends. The choice for an appropriate regional level is taken individually by country, taking into account sample size requirements of multi-level models (as treated in Racioppi and Rivellini, 2001), the availability of regional data according to national statistical systems, and the regional identifier available in the national GGS.

Besides the general link of individuals to context by time and region, different population groups find themselves in very specific contexts. According to the importance of the generations and gender perspective in the program, contextual data are frequently provided by sex and age group. Other important population groups are constructed by marital status, educational attainment, and occupation. In order to determine the policy contexts for individuals of different characteristics, the description of policy measures emphasizes especially the concepts of eligibility.

The Contextual Database is a comparative database: the same set of variables is collected for all participating countries, following the same definitions. In practice, this has proven difficult for various reasons. For many variables, there exist competing definitions used in different international databases covering different sets of countries. For other variables, international definitions became standards only recently, not allowing the collection of time-series data according to them. As a general rule, we aim at capturing variations over time as fully as possible; this, however, sometimes restricts us to use the national definitions. Shorter, comparable time-series are then provided additionally.

\subsection{Context types and measurement dimensions}

The Contextual Database distinguishes between two partly overlapping theoretical concepts of context assumed to influence individual behavior: the normative one statistical and legal norms - and the welfare state context, expressed in policies and their underlying values.

\subsubsection{Norms}

Statistical norms refer to regular behavior; a behavioral pattern becomes a norm if the majority of actors behave according to this pattern. Thus, norms are objectively observable and measurable, e.g. by means and distributions of individual events and characteristics. In difference to the descriptive concept of norms, legal norms are prescriptive and valueoriented: they are social facts that are not identified directly but rather through the existence of certain sanctions.

In the contextual database, we include statistical norms in the form of mean values and age distributions of key demographic events, e.g. the mean age at childbearing and marriage, assuming that individuals orient their behavior also towards such observable averages. Many economic indicators fall into this group. As statistical norms change over time, they can serve as indicators of the developmental stages, assuming universal transition mechanisms as in demographic transition theory. In this sense, statistical norms can be 
used as indicators of the prevalence or emergence of certain behaviors (e.g., unmarried cohabitation). Statistical norms are also important in the context of policies, where they constitute important outcome variables, e.g., measuring enrolment and take-up rates.

Legal regulations influence individual behaviors in various ways. They impose important timing norms that impact the key domains of the individual life course. This is especially true for education systems that e.g., define the minimum compulsory time of schooling. Important timing norms are set by work time regulations, paid maternity leave periods, the conscription age, or the legal retirement age. Legal norms impose important quality standards, e.g., staff requirements of childcare institutions, which may impact individual decisions on the organization of care. They define family responsibilities and may restrict, prohibit or regulate certain behaviors and personal relations, with examples being abortion laws, divorce regulations, and the legal treatment of same-sex partnerships. Variables that describe legal norms are found in most of the topical sections of the Contextual Database; legal regulations of personal relations constitute a database topic by themselves.

\subsubsection{Welfare state context}

The welfare state context is expressed in policies and their underlying social values and concepts. Policy data constitute key variables of the Contextual Database; concerning the selection of the aggregation level and data types of policy variables, we followed a mixed approach combining policy indicators on the level of individual policy measures with indicators and text descriptions on highly aggregated and abstract levels. The selection of measurement dimensions and eventually of the database variables is heavily influenced by concepts developed in welfare state research and an in-depth study of existing policy databases.

Policy data provided by the Contextual Database can be classified into four main groups reflecting different aggregation levels and approaches of policy analysis.

The first group consists of short text descriptions of the key characteristics of policy fields and social security institutions in the form of policy histories, i.e. recording major changes and identifying and characterizing time episodes since 1970. This variable type is used both for the description of broad policy fields (e.g. housing policies) and for the collection of information on very specific policy-related questions (e.g., which policies exist to promote part-time work?). The variable definition includes keywords indicating which information to collect in order to capture the key policy dimensions. Variables of this type are frequently combined with a set of numerical indicators. The use of this information type is two-fold. First, it aims at providing a focused overview on the national policy context by providing qualitative information on the key characteristics of policy domains as well as on the principles and priorities underlying governmental action. Second, it supports the study of policy effects by identifying time episodes characterized by certain (combinations of) policies. 
A second type of variables concerns political actors. The development of welfare states involves and reflects the efforts and struggles of competing interest groups to gain political influence and to lobby policy makers to their course. In the Contextual Database, this approach is reflected in the collection of information on the main political parties as well as their participation in government coalitions, as very often it is consensual politics that shapes certain policies.

The third group of variables widely used as measures of the welfare state are social (and other public) expenditure. While the general level of social expenditure gives some indication of the extent to which a state engages in the provision of economic and social security etc., the study of how spending is distributed between different categories provides additional information. The Contextual Database concentrates on the functional perspective of public expenditures, focusing on their purpose, e.g. , the extent to which provisions are allocated to certain means and - explicitly or implicitly - to population groups, e.g., age groups. The Contextual Database provides time-series data on public (and for some concepts also of total) expenditures for nine selected means: active labor market programs, unemployment benefits, elderly care services, housing, pre-school childcare, education, health, total social expenditures, and military expenditure.

Besides these highly aggregated and abstract indicators discussed so far, the Contextual database contains detailed standardized descriptions and quantifications of key features of selected single policy measures, most importantly parental leave institutions and childcare provision. One of the challenges of the Contextual Database was the development of standardized schemes that capture all important dimensions of policies and suit a wide set of possible policy designs.

Except for expenditure data, this classification still has to be complemented by a selection of key measurement dimensions along the question of which aspects of the welfare state and its policies and actors should be included in the Contextual Database.

An important general measurement dimension directly linked to the timing of life-course events is time itself expressed e.g., in the length of parental leave periods and constituting important timing norms. Besides setting norms, the welfare state influences individual behavior through various other channels. Measures of the Contextual Database thereby cluster around four main concepts derived from comparative welfare state research: social and economic rights; equality; risks and security; and individual agency. (A description of welfare state concepts which heavily influenced the selection of variables is given in Neyer (2003); the remaining section is based on this contribution).

The term "welfare state" is closely linked to Marshall's (1950) concept of social citizenship, based on the recognition of material and social needs and giving rise to economic and social rights. An influential way of specifying social citizen rights is linked to Esping-Andersen's concept of de-commodification: a weakening of the connection between income and market participation (Esping-Andersen 1990). The degree to which 
policies and social security systems are designed in recognition of social and economic rights is reflected in legal entitlements, eligibility, coverage, the linkage of benefits to individual contributions, and the existence and level of minimum standards, e.g., minimum benefits or the quality standards of services. A good example of this concept is the recognition of fulltime childcare as a social right in Scandinavian countries.

The concept of equality refers to the cross-sectional differentiation of living conditions and the equality of life chances, e.g., the distribution of opportunities, resources and capabilities, including their intergenerational transmission. Equality has important gender, generational, and class dimensions. Measures of the extent of equality are participation and enrolment rates (e.g., labor-market participation by sex and age) and the distribution of e.g., income. Policy dimensions reflecting equality concepts include benefit eligibility and coverage, public sector involvement in service provision (e.g., schools), the existence and mechanisms of measures to provide access to services and markets (e.g., housing, education), the treatment of unmarried and same-sex partnerships, the special protection of institutions, such as the family, and affirmative actions to actively promote equality.

Risks and security deal with the likeliness of unfavorable events, e.g. unemployment and sickness, the consequences of such events, e.g. poverty and dependence, how these risks and consequences are related to the life-course events and relations, and the ways in which the state impacts these risks and consequences. Risks directly addressed in the database are poverty and unemployment. Important policy dimensions are replacement rates, including the underlying concept (e.g., poverty prevention vs. status maintenance), durations (of benefits; average durations of unemployment) and the treatment of unpaid care work by the pension system.

Agency refers to a set of choices, the ability to choose, and to the incentive system that influences the choice to be made, including the individual's bargaining position within the family. The concept of agency is frequently combined with the concept of equality in terms of 'equality in the freedom to achieve' and is especially useful for the study of gender differentials (Korpi 2000). Policies interfere with agency in various ways, addressed in the Contextual Database: the economic burden and time commitment associated with behaviors studied in the GGP: e.g., costs and opening hours of childcare institutions; the flexibility of policies (influencing the set of choices, e.g., the deferability of parts of leave periods); and incentives to promote gender equality, e.g. in the organization of paid and unpaid work, and the take-up of leave periods.

\subsection{A database to complement the GGS: Topics and Variables}

In this section, we present the 16 topics or domains of the Contextual Database, their relation to the GGS, and the list of variables by domain. The selection process of appropriate database topics is based on a structured inventory of the micro-level information collected by the survey. The choice of variables is then made following the 
theoretical considerations described in the sections above. Concerning the study of the information content of the panel survey, we first follow a life course perspective. Two survey focal points that are not fully captured by this approach and therefore studied separately are socio-economic variables and values.

Apart from theoretical concepts, the selection of variables is heavily influenced by a series of existing international databases. The Contextual Database distinguishes itself by the set of countries participating in the GGS: these are usually not covered together in any single existing database. A second distinction, mainly concerning policy information, is the longitudinal dimension of the Contextual Database: while many variables can be found in existing policy databases, most of them are limited to cross-sectional information.

\subsubsection{Life-course context}

\section{The individual life course and its context}

The life course refers to 'a sequence of socially defined events and roles that the individual enacts over time' (Giele and Elder 1998, p. 22). These life-course events are central issues in the GGS and constitute key dependent variables.

The life-course perspective goes hand in hand with a certain description of human biographies as event histories, with clearly defined states and events belonging to different domains. The description of individual lives by means of event-history data is not independent of the context. For example, the activity status "on parental leave" depends on the existence of parental leave regulations. This places individual choices into a context that may vary considerably between countries. The GGS distinguishes several such domains, with most of their various states and dimensions displaying a direct link to contextual domains.

A first group of life-course information collected in the GGS concerns demographic events. Here, births and partnership transitions constitute central dependent variables; the survey contains full birth and partnership histories. Fertility and partnership events are related to many contextual domains of the database, and the existence of hypotheses linking the contextual variables to these events constitutes one of the main selection criteria of variables. The health dimension is another domain closely related to life itself. In the GGS, data is collected on current illness, disabilities (including some retrospective information), care needs, and wellbeing. Data on limitations in daily activities are collected for all household members as well as for parents and children in order to obtain information on possible care needs in the family network. Corresponding contextual information can be found under the headings below.

Topic 1 - General demographic indicators: a brief selection of key demographic indicators on the national and regional level. The behavioral focus lies on the classic demographic events of birth, marriage, divorce, migration, and life expectancy; additional topics are abortion and single motherhood. 


\begin{tabular}{|ll|}
\hline National level & \multicolumn{2}{l|}{ National and regional level } \\
- $\quad$ Age-specific fertility & - Total Fertility Rate \\
- Cohort mean age at birth & $-\quad$ Life births (all, first) \\
- Induced abortions & - Marital life births \\
- First marriage rate female & - Mean age at birth (all, first) \\
- Cohort ever married & - Marital status by age and sex \\
- Marriage by ethnic group & - Population by age and sex \\
- Total divorce rate & - Mean age at first marriage \\
$-\quad$ Median marriage duration & - Marriages (all, first) \\
$-\quad$ Median age & - Single parents \\
$-\quad$ Net migration & - Divorces \\
\hline
\end{tabular}

Topic 2 - Health and health care system: the contextual variables include measures on healthy life expectancy as well as general, maternal, and infant mortality. We also aim at describing the main features of the national health care system.

\begin{tabular}{|lll|}
\hline National level & \\
$-\quad$ Health care system description & - & Healthy life expectancy \\
- Health expenditures & - & Infant mortality \\
- Health insurance coverage & - & Physicians per 10000 \\
$-\quad$ Maternal mortality & - & Hospital beds per 10000 \\
\hline
\end{tabular}

An important life course domain in the GGS concerns activities. The survey distinguishes between various main activities, e.g. working, retirement, on parental leave, unemployed, in education, in National Service. Information on the main activity is collected for all household members. Detailed questions regard the respondent's and partner's current job and/or education and intentions to start or resume work. Full activity histories are to be collected during the second wave. Again, we establish a close link between individual states and contextual domains, which are:

Topic 3 - Labor and employment: a selection of indicators including gendered labormarket participation, sectoral employment, wages and wage distributions, and work related regulations and polices. Concerning the latter, we focus on measures that impact the reconciliation of work and family life: work time regulations, policy information on the promotion of part-time work, legal entitlement to part-time work, standard hours, extra compensation for work during non-standard hours, and measures to reduce work during non-standard hours. 


\begin{tabular}{|c|c|}
\hline National level & National and regional level \\
\hline - Weekly hour-bands by sex & - $\quad$ Labor-market participation by sex \\
\hline - Normal working hours & - Employment by ISIC and sex \\
\hline - Minimum vacation days & - $\quad$ Public employment by sex \\
\hline - Average vacation days & - Wage by age and sex \\
\hline - Entitlement to part-time & - Wage deciles by sex \\
\hline - Measures to increase part-time & \\
\hline - Nonstandard hours - measures & Regional level \\
\hline - Nonstandard hours - compensation & - Employment mothers \\
\hline - Wage by activity and sex & - Employment fathers \\
\hline - $\quad$ Minimum wage & - Average wage \\
\hline $\begin{array}{l}\text { - Public expenditures for active labor } \\
\text { market policies }\end{array}$ & \\
\hline
\end{tabular}

Topic 4 - Unemployment and unemployment system: We focus on three aspects of unemployment: unemployment rates by individual characteristics such as age, sex, and education; measures on the duration of unemployment; and the main characteristics of the unemployment insurance system.

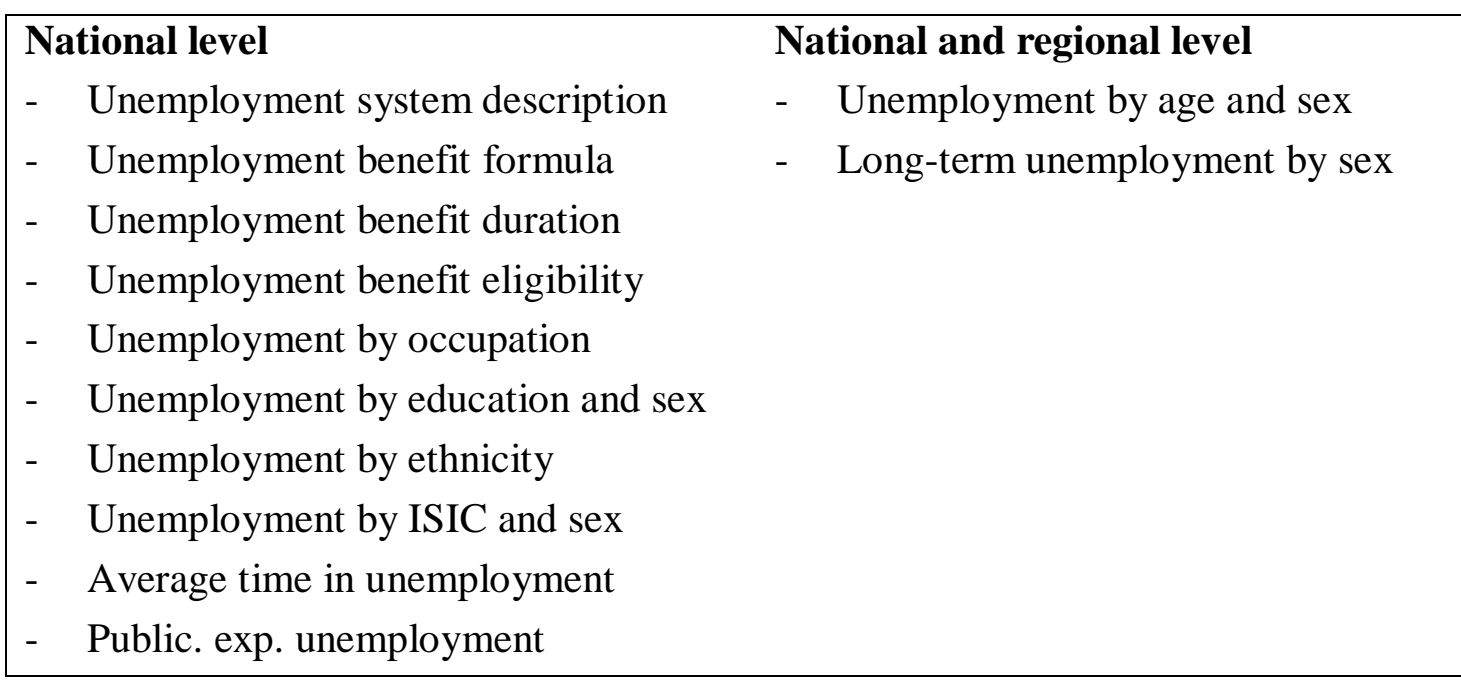

Topic 5-Pension system: indicators focus on retirement age and system descriptions, e.g., the link of contributions to benefits and the extent to which child and family care are accounted for. 


\begin{tabular}{|c|c|}
\hline \begin{tabular}{ll}
\multicolumn{2}{l}{ National level } \\
- & Pension system description \\
- & Legal retirement age \\
- & Average retirement age \\
- & Link contribution - benefit \\
- & Care and pensions \\
- & Minimum pension \\
- & Pension spending \\
- & Pension receivers
\end{tabular} & $\begin{array}{l}\text { National and regional level } \\
-\quad \text { Average pension }\end{array}$ \\
\hline
\end{tabular}

Topic 6 - Parental and care leave systems: the database provides a detailed standardized table of variables for all national maternity, parental, and childcare leave systems. Indicators include eligibility, timing, cash compensation, and the flexibility of leave systems.

\section{National level}

- Comparative table of leave systems - for each system:
○ Title of program
○ Eligibility
○ Start of leave
○ Regular duration
- Maximum shareable duration
- Duration reserved for partner
- Duration of parallel paternal leave
○ Duration of financial
- Type of financial compensation compensation
- Deferrable time
- Compensation formula
- Deferrable until
- Means tests
○ Duration/payment options
○ Compatibility with work

- Child sick leave

- Take-up-time of leave

Topic 7 -Military system and national service: the indicators focus on the service age and service durations of compulsory military and civilian services and the range of choices concerning service type and timing. 


\begin{tabular}{|lll|}
\hline National level & & \\
- Description National Service & - & Alternative service \\
- Conscription age & - & Reconciliation family and military \\
- Duration National Service & - & People in Armed Forces \\
$-\quad$ Population exempt & - & Military expenditure \\
\hline
\end{tabular}

Topic 8 -Education: the data cover various aspects of education, including a description of the national school system, timing norms such as entry age and school duration, standard school hours, enrollment rates and educational attainment, school finance, and school quality.

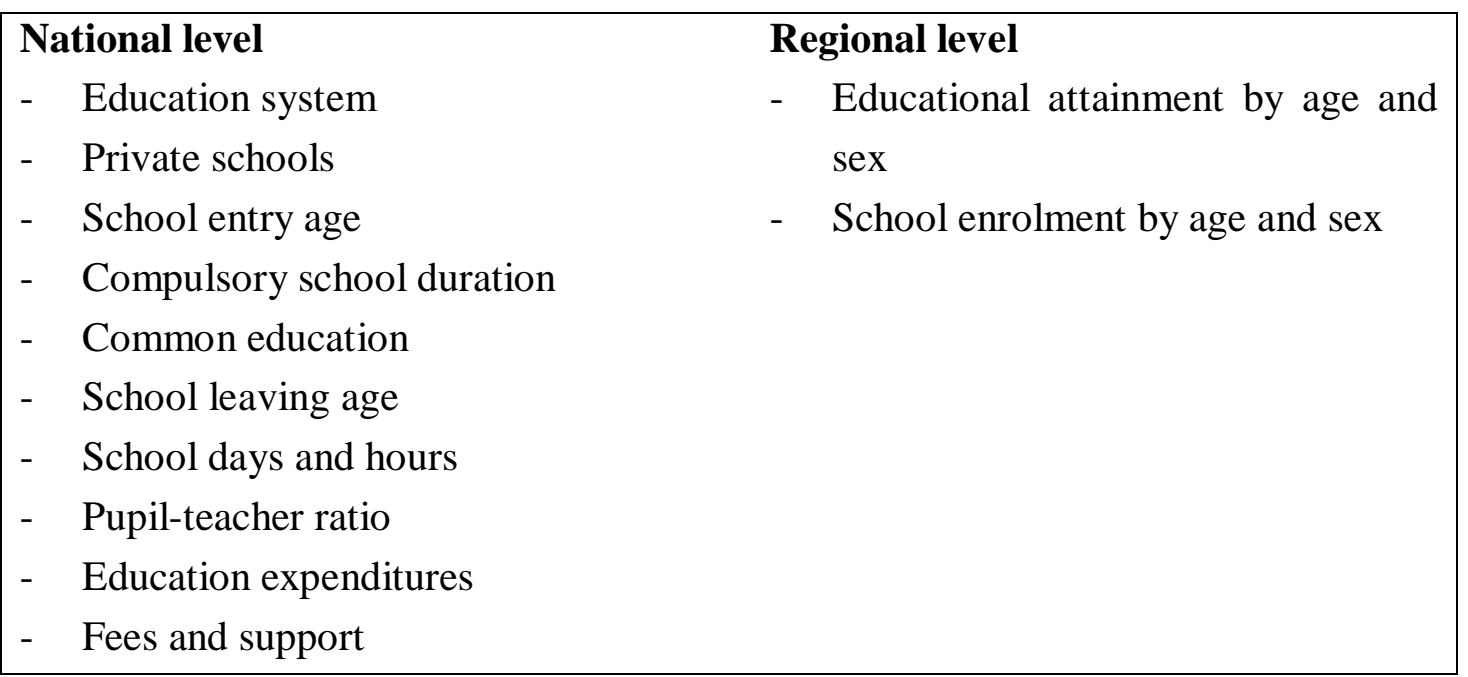

\section{Relations}

A second important component of the life course perspective is the concept of "linked lives" - i.e., the relations between people. With it being a "Generations and Gender" Survey, gender and (inter-)generation relations constitute a key area of information. Data on relations are collected for persons in the household, all (ex-) partners, children and parents as well as other persons if they are important providers or receivers of care. Personal relations are investigated in various dimensions, including their legal nature, coresidence, intensity, satisfaction, quality, power of decision making, money, and time. One of the key areas of relations is the organization, interchange, and provision of care, which constitutes a central link between gender and generational relations. The Contextual Database complements the individual-level information in the following fields:

Topic 9 - Legal regulations of personal relations: including information on marriage and divorce regulations and restrictions, restrictions on abortions and legal obligations concerning care. 


\begin{tabular}{|c|c|}
\hline \multicolumn{2}{|l|}{ National level } \\
\hline - Abortion restrictions & - Divorce restrictions \\
\hline - $\quad$ Social security abortions & - Guardianship \\
\hline - $\quad$ Same-sex partnerships & - Care obligations \\
\hline
\end{tabular}

Topic 10 - Childcare: contextual data concern the availability of care institutions as well as costs, and the extent to which they are shared between parents and the public, the quality of childcare institutions, the existence of legal entitlements to institutional care, enrollment rates, and timing norms such as (pre)school entry ages and typical school hours.

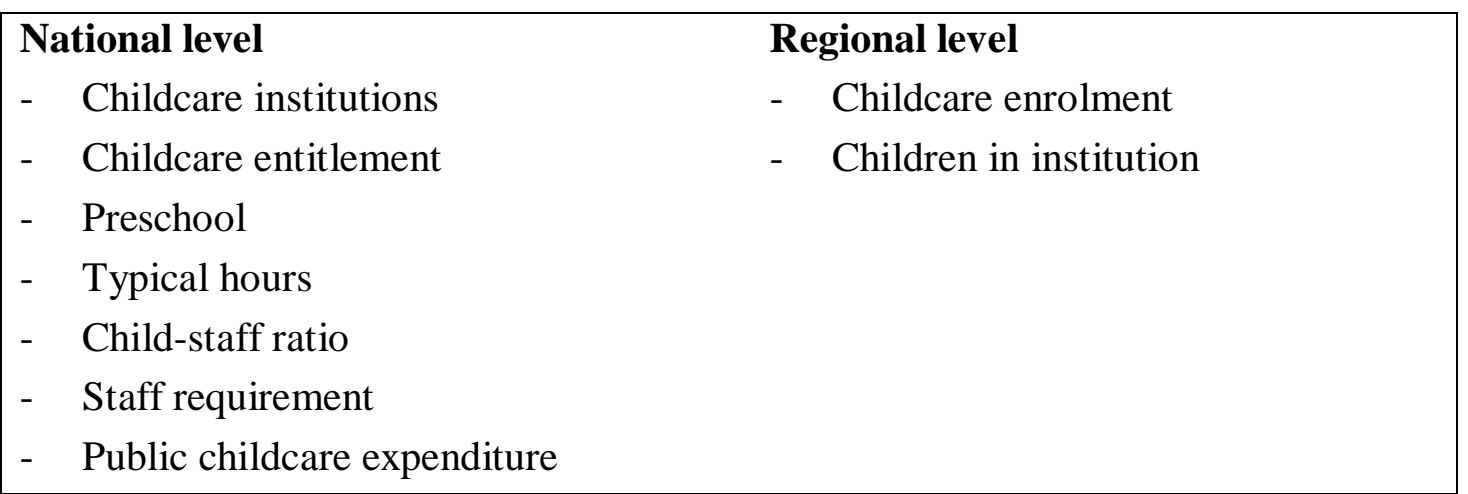

Topic 11 - Elderly care: this database section contains measures that support elderly in need of care, supportive measures for care givers, and general indicators on people receiving institutional care of different types.

\section{National level}

- Elderly care measures

- Pension benefit for care giver

- Elderly in institutions by sex

- Measures for care-givers

- Home care by sex

- Public expenditure elderly care

\subsubsection{The socio-economic situation}

The socio-economic situation of the respondent and the household is usually closely linked to employment and other activities. The GGS collects information on labor and transfer incomes, wealth, and some selected expenditures on care and household services. This information is complemented by the contextual data of three domains: 
Topic 12 - Economy: this database section consists of a selection of general economic indicators that are not directly linked to specific activity statuses: economic output, growth, stability, income distribution, and poverty.

\begin{tabular}{|ll|}
\hline National level & \multicolumn{2}{l|}{ Regional level } \\
- Real GDP per capita & - HH income deciles \\
- CPI & - Poverty - children \\
- GINI coefficient & - Poverty - mothers \\
- Poverty by age and sex & - Poverty - active age \\
- Poverty by activity and sex & - Poverty - elderly \\
- Poverty by HH-type & - GINI coefficient \\
\hline
\end{tabular}

Topic 13 - Housing: Information on housing stock and housing production by type, general housing situation, and relevant housing policies.

\section{National level}

- Housing situation

- Housing policies

- Housing construction

- Housing stock

- Public expenditures on housing

- Living arrangement by sex

\section{Regional level}

- Average dwelling size

Topic 14 - Tax-Benefit system: including tax rates, child benefits, and the impact of marriage on taxes and benefits

\begin{tabular}{|c|c|}
\hline National level & \\
\hline - Income tax system & - Social security contribution \\
\hline - Marginal income tax rate & - Social expenditure \\
\hline - VAT-rate & - $\quad$ Marriage and taxes/benefits \\
\hline - Child benefits & \\
\hline
\end{tabular}

\subsubsection{Culture and Values}

The GGS includes a section on attitudes and value orientations on gender and intergenerational relations as well as on religiousness. The individual-level data is placed within the context of the cultural, political, and religious heritage of a country or region: 
Topic 15 - Culture: selected indicators on the religious, linguistic, and ethnic composition of the population.

\begin{tabular}{|ll|}
\hline National level & Regional level \\
$-\quad$ Internet use & - Religious composition \\
& - Language composition \\
& - Ethnical composition \\
\hline
\end{tabular}

Topic 16 - Political system: information on the main political parties and government coalitions.

\begin{tabular}{|ll|}
\hline National level & National and regional level \\
$-\quad$ Political parties & $-\quad$ Government coalitions \\
\hline
\end{tabular}

\section{Summary}

The Generations and Gender Contextual Database is a theory-based instrument of the Generations and Gender Program complementing the individual-level data collection of the Generations and Gender Survey. The database provides time series, policy history, and regional-level data on sixteen topics and is designed to support the integration of microand macro-level approaches of analysis. The contextual database allows to reach beyond the mere analysis of single countries in that it considers the extent to which differences in contexts shape demographic processes, and offers the opportunity to conduct comparative studies on the interaction between the micro and macro dimension.

\section{Acknowledgements}

I am thankful to all members of the Contextual Database Working Group and workshop participants ${ }^{4}$ who actively contributed to the design and development of the Contextual Database, and to Susann Backer for careful language editing of this contribution.

\footnotetext{
${ }^{4}$ See Appendix.
} 


\section{References:}

Esping-Andersen Gøsta (1990) Three Worlds of Welfare Capitalism; Polity Press, Cambridge

Festy, Patrick (2001) Designing a Macro-Context for the Generations and Gender Individual Data, Presentation at the first meeting of the Informal Working Group of the Generations and Gender Program in Budapest 2001 http://www.unece.org/ead/pau/ggp/iwg/Budapest/festy.pdf

Giele, Janet Z. \& Elder, Glen H. (Eds.) (1998) Methods of Life Course Research: Qualitative and Quantitative Approaches, Thousand Oaks, Sage

Goldscheider, Frances K. (2000) Realizing the Potential of FFS1 with Contextual Data, Presentation at the FFS Flagship Conference 2000, http://www.unece.org/ead/pau/flag/goldscheider.pdf

Korpi, Walter (2000) Faces of Inequality: Gender, Class, and Patterns of Inequalities in Different Types of Welfare States; Social Politics, Summer 2000

Marshall, Thomas Humphrey (1950) Citizenship and Social Class and Other Essays. Cambridge, Cambridge University Press

Neyer, Gerda (2003) Gender and Generations Dimensions in Welfare-State Policies. Rostock, MPIDR Working Paper WP-2003-022. http://www.demogr.mpg.de/papers/working/wp-2003-022.pdf

Racioppi, Filomena \& Rivellini, Giulia (2003) The Contextual Dimension in GGP: Some Methodological Issues About Data Collection and Sampling Procedures http://www.unece.org/ead/pau/ggp/iwg/Prague/cdbasegr.pdf

Spielauer, Martin, (2004a). The Contextual Database of the Generations and Gender Program: Overview, Conceptual Framework and the Link to the Generations and Gender Survey. Rostock, MPIDR WP-2004-014 http://www.demogr.mpg.de/papers/working/wp-2004-014.pdf

Spielauer, Martin, (2004b) The Generations and Gender Contextual Database: Concepts and Content. Rostock, MPIDR WP-2004-026 http://www.demogr.mpg.de/papers/working/wp-2004-026.pdf 


\section{Appendix: Members of the Contextual Database Working Group and Workshop Participants}

The conceptual framework of the Contextual Database was developed and discussed by an international group of experts of various fields and institutions - the Contextual Database Working Group, constituted in 2002. Additionally, various national experts participated in a concluding workshop contributing to the final choice of variables and variable definitions by providing information on the feasibility of data collection in the various national contexts. The following list presents the persons who have contributed to the development of the conceptual framework of the database and/or its discussion in meetings and workshops.

Members of the Contextual Database Working Group:

- Enrico Bisogno

- Patrick Festy

- Jacques Légaré

- Alphonse MacDonald

- Tereza Munzi

- Gerda Neyer

- Antonella Pinelli

- Filomena Racioppi

- Giulia Rivellini

- Martin Spielauer
United Nations, Population Activities Unit (PAU), Geneva

INED, Paris; Coordinator until mid 2003

Statistics Canada, Ottawa

United Nations, Population Activities Unit (PAU), Geneva

Luxembourg Income Studies, Luxembourg

Max Planck Institute for Demographic Research, Rostock

University La Sapienza, Rome

University La Sapienza, Rome

Catholic University Sacre Cuore, Milan

Coordinator, Max Planck Institute for Demographic Research, Rostock

National experts:

- Aline Désesquelles

- Gert Hullen

- Dora Kostova

- Jaroslav Kraus

- Věra Kuchařová

- Jitka Rychtaříková

- Norbert Neuwirth

- Oxana Sinyavskaya

- Akos Tarknyi

- Sergei Zakharov
INSEE, Paris

German Federal Statistical Office, Wiesbaden

Bulgarian Center for Population Studies, Sofia

Charles University Prague

Research Institute for Labor and Social Affairs, Prague

Charles University Prague

Austrian Institute for Family Studies, Vienna

Independent Institute for Social Policy, Moscow

Hungarian Statistical Office, Budapest

Independent Institute for Social Policy, Moscow 